\title{
Positron Annihilation Studies of Reactor Pressure Vessel Steels Treated by Hydrogen Ion Implantation
}

\author{
V. Slugen ${ }^{a}, *$ S. PeCKO ${ }^{a}, \mathrm{~S} \mathrm{SOJAK}^{a}, \mathrm{~W} . \mathrm{EGGER}^{b}$, \\ M. SARO ${ }^{a}$ AND M. PETRISKA ${ }^{a}$ \\ ${ }^{a}$ Institute of Nuclear and Physical Engineering, Slovak University of Technology, \\ Ilkovičova 3, 81219 Bratislava, Slovakia \\ ${ }^{b}$ University of Bundeswehr, Werner Heisenberg Weg 39, Munich, Germany
}

\begin{abstract}
Long term operation of nuclear reactors is one of the most discussed challenges in nuclear power engineering. Radiation degradation of nuclear materials limits the operational lifetime of all nuclear installations or at least decreases its safety margin. This paper is focused on experimental simulation and evaluation of materials via hydrogen ion implantation and on comparison with our previous results obtained from neutron-irradiated samples. In our case, German reactor pressure vessel (RPV) steels, originally from CARINA/CARISMA program, were studied by positron annihilation lifetime spectroscopy (PALS) and the pulsed low energy positron system (PLEPS) with the aim to study microstructural changes in RPV steels after high level of irradiation. Unique specimens were irradiated by neutrons in the German experimental reactor VAK (Versuchsatomkraftwerk Kahl) in the 1980s and these results were compared with the results from a high level of hydrogen nuclei implantation. Defects with sizes of about 1-2 vacancies with relatively small contributions (with intensity on the level of 20-40\%) were observed in all "as-received" steels. An increase in the sizes of the induced defects (2-3 vacancies) due to neutron damage was observed in the irradiated specimens. On the other hand, the size and intensity of defects reached extremely high values due to displacement damage caused by implantation of hydrogen ions in a very narrow damaged region. This fact can be a limiting factor in the operation of new fission or fusion nuclear facilities.
\end{abstract}

DOI: 10.12693/APhysPolA.137.238

PACS/topics: Radiation damage, neutron embrittlement, ion implantation, positron annihilation, reactor pressure vessel steels

\section{Introduction}

The safety and life extension of nuclear power plants (NPPs) is a very actual issue nowadays, when more than $50 \%$ of operated NPPs have achieved their projected lifetime. Reactor Pressure Vessel (RPV) is important component which determines, due to almost not possible replacement, the overall life of the whole nuclear facility. It is necessary not only to know the condition and degradation level of RPVs in detail but also to predict their behaviour trend towards the future [1].

It is well-known that RPV steels exposed to neutron irradiation in a reactor during the long-term operation will age over time via accumulated radiation damage. The traditional method of studying radiation damage effects is conducted by irradiating the samples in test reactors. However, several serious drawbacks impeding our understanding of radiation effects in test reactors should be mentioned. Firstly, the irradiation parameters (irradiation temperature, dose, flux) of a test reactor are generally difficult to control. Secondly, experiments within the reactor neutron irradiation environment are usually time-consuming (several years), expensive, and not safe enough (samples become very radioactive) [1]. It seems

*corresponding author; e-mail: vladimir.slugen@stuba.sk that a promising solution to these problems is the use of ion irradiation as a substitute for the simulation of radiation damage produced by neutron irradiation. Relevant parameters of ion irradiation are much better controlled than irradiation in the reactor and the evolution of the radiation-induced defects can even be observed in situ. One of the crucial factors is the penetration depth of ion implantation which depends on the type and energy of the particles used: electrons, light ions $(\mathrm{H}, \mathrm{He})[2,3]$, and heavy (or self) ions [4]. Typical low energy proton beam or several $\mathrm{MeV}$ self-ions damaged layers have a thickness of the order of one micrometer below the surface of the irradiated samples. Hence, the detailed microstructural evolutions in this thin irradiated layer $(\sim$ $\mu \mathrm{m}$ ) should be characterized by depth-sensing methods. PALS using variable mono-energy positron beams allows one to probe the depth profile of the surface and nearsurface defects in ion-irradiated structural materials and has been successfully applied to study microstructural evolutions in RPV steels [5-8]. In the past decades, a growing body of evidence showed that proton irradiation can emulate the neutron irradiation-induced microstructural features, which provides a basis for its use in screening new structural materials in current and advanced future reactors, while much less experiments have been done to benchmark Fe (i.e., self)-ion irradiation. In this paper, we focus on the evaluation of differently treated German RPV steels from the positron annihilation point 
of view. We had the possibility to apply a pulsed low energy positron beam which is very suitable for the deep scanning of a relatively thin region where the implantation was performed. These newest results were correlated with our previous PALS studies on identical specimens treated by neutrons published in [9].

\section{Experimental}

Studied specimens in form of two pieces from each material assembled in a sandwich set-up were delivered from AREVA NP GmbH Erlangen, Germany and belong to the family of commercial RPV steels used since the 70's. Results from mechanical studies in frame of research programs CARISMA and CARINA were published in [10]. Fortunately, they were very suitable also for our positron annihilation studies due to more than 35 years of decay of ${ }^{60} \mathrm{Co}$ after irradiation. The irradiation temperature ranged between 280 and $290^{\circ} \mathrm{C}$. Chemical composition of the studied steels is listed in Table I.

Two different specimens from the bulk material were cut from the irradiated materials. The specimens were treated by neutron fluence up to $2.23 \times 10^{19} \mathrm{~cm}^{-2}[9]$. The content of $\mathrm{Cu}$ and $\mathrm{Ni}$ should affect the final radiation damage inflicted by the negative impact of these impurities on radiation and mechanical properties. Based on the suggestions of Stoller et al. [11], the following variables were applied in the newest SRIM calculations: displacement energy $40 \mathrm{eV}$, lattice binding energy $0 \mathrm{eV}$, type of TRIM calculation - "Quick damage calculation".

The simulation from SRIM code for hydrogen implantation in the RPV steel shows that the maximum implantation depth is about $0.64 \mu \mathrm{m}$ with a damage peak at about $0.44 \mu \mathrm{m}$. On average, 5 vacancies were produced per implanted ion. The implantation was performed with three fluencies where the final fluence was equal to the neutron fluence from the CARINA/CARISMA program $\left(2.2 \times 10^{19} \mathrm{~cm}^{-2}\right)$ [see Table II]. For the sake of simplicity, displacement per atom (dpa) was averaged over the first $1 \mu \mathrm{m}$ thick region.

TABLE I

Chemical composition of Specimen P370 WM in wt \% (Fe balance) [10].

\begin{tabular}{c|c|c|c|c|c|c|c|c|c}
\hline \hline Elem. & $\mathrm{C}$ & $\mathrm{Si}$ & $\mathrm{Mn}$ & $\mathrm{P}$ & $\mathrm{S}$ & $\mathrm{Cr}$ & $\mathrm{Mo}$ & $\mathrm{Ni}$ & $\mathrm{Cu}$ \\
\hline wt\% & 0.08 & 0.15 & 1.14 & 0.015 & 0.013 & 0.74 & 0.60 & 1.11 & 0.22
\end{tabular}

TABLE II

Overview of implanted parameters in specimen.

\begin{tabular}{c|c|c|c}
\hline $\begin{array}{c}\text { Level of } \mathrm{H} \\
\text { implantation }\end{array}$ & $\begin{array}{c}\text { Implanted } \\
\text { dose }\left[\mathrm{C} / \mathrm{cm}^{2}\right]\end{array}$ & $\begin{array}{c}\text { Number of } \\
\text { implanted } \\
\text { ions }\left[\mathrm{cm}^{-2}\right]\end{array}$ & $\begin{array}{c}\text { Dose in } \\
\text { implanted } \\
\text { region [dpa] }\end{array}$ \\
\hline 1 & 0.10 & $6.24 \times 10^{17}$ & 0.5 \\
2 & 0.82 & $5.12 \times 10^{18}$ & 4 \\
3 & 3.20 & $2.21 \times 10^{19}$ & 15
\end{tabular}

It is important to note that the depth profile of positrons from the ${ }^{22} \mathrm{Na}$ source results in probing of a much deeper region than the one modified by $100 \mathrm{keV}$ $\mathrm{H}$ implantation. In fact, only about $<10 \%$ of the positrons stop in the implanted layer, providing most of the information from the undisturbed bulk region [12]. Therefore, it is reasonable to reduce the obtained dpa values by one order of magnitude, giving the final "visible" damage of $0.05,0.4$, and $1.5 \mathrm{dpa}$, respectively for the three levels of the implanted damage.

\section{Results and discussion}

Previous PALS studies on neutron-irradiated specimens [9] used a two-component analysis with lifetimes $\tau_{1}$ and $\tau_{2}$ and corresponding intensities. It was proven that performed irradiation treatment caused an increase of positron lifetimes in the studied specimens caused by increased positron trapping at the probably $\mathrm{Cu}$-rich solute clusters or vacancy-Cu complexes. The lifetimes $\tau_{2}$ of about $195-200$ ps indicate the presence of small vacancy clusters of about 1-2 vacancies. In the case of steel P370 WM, the lifetimes in defects are longer with values of about 203 and 213 ps. It could indicate vacancy clusters of $2-3$ vacancies $[9,13,14]$.

Despite a low sensitivity of the conventional PALS to the near-surface damage produced by low-energy ionimplantation, an increase of positron trapping at defects was observed in $\mathrm{H}$-implanted samples comparing with the unirradiated condition. Differences to un-irradiated specimens were significant, but differences between neutron irradiated and hydrogen ions implanted samples were almost inside error bars [9].

In our previous studies [12] we concluded that only $7-10 \%$ of the information obtained by the conventional PALS technique comes from the near-surface region of about $600 \mathrm{~nm}$. Therefore, this comparison was only preliminary. For more precise verification, we measured the mentioned specimens also by Pulsed Low Energy Positron System (PLEPS) at FRM-II reactor in Garching (NEPOMUC, Germany) [15, 16]. This unique system allows depth profiling of defects in the range up to $600 \mathrm{~nm}$.

PLEPS results confirm our preliminary PALS results for the as-received sample (Fig. 1). In the depth of about $500 \mathrm{~nm}$, where back-diffusion does not play any role, the lifetimes $\tau_{1}$ and intensities $I_{1}$ are comparable. Large defect agglomerations are rare (closed to about $2 \%$ ). In the pictures, clear differences are visible between implanted and as-received specimen. Implantation increases not only the mean lifetimes in the whole profile (as expected) but in the implanted region dramatically increases the concentration of large vacancy complexes $\left(I_{2}\right)$. Defect component with lifetime $\tau_{2}>400 \mathrm{ps}$ and intensity of about $70 \%$ indicates an extremely damaged region. Microstructural damage of the specimen after $\mathrm{H}^{++}$ion implantation (15 dpa) was much higher than in the case of neutron irradiation (although the fluence 


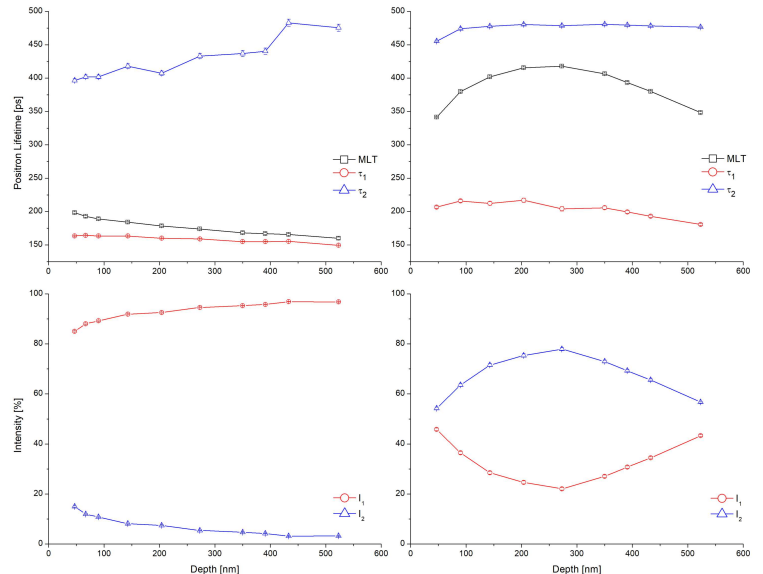

Fig. 1. Comparison of PLEPS parameters of specimen P370 WM before (left) and after (right) hydrogen ions implantation.

was almost the same - of about $2 \times 10^{19} \mathrm{~cm}^{-2}$, all damages were in very thin region - about $400 \mathrm{~nm}$ ). This big difference could be explained by a much higher energy of primary and secondary knock atoms in the case of $\mathrm{H}^{++}$implantation in the most loaded region due to the selected depth in contrast to the neutron irradiation which was performed to the whole volume.

Hydrogen ion implantation changed this first component via a slight increase of lifetimes and a significant decrease of intensities which can be caused due to introduction of new radiation-induced vacancies. The second component could be assigned to large defects (agglomeration of about 50-100 vacancies in voids). Before ion implantation, the intensity was on the level of several percent, and after implantation it increased to $75 \%$ in the most damaged region. From these results we can conclude that implantation of hydrogen ions on the level of 15 dpa in a relatively thin region $(100-600 \mathrm{~nm})$ under the surface (see Fig. 2) severely damaged the studied microstructure in the depth of about $400 \mathrm{~nm}$. The deepest PLEPS measurement (at about $530 \mathrm{~nm}$ ) also shows a higher shift of positron lifetimes and intensities after ion implantation than neutron irradiation. In Fig. 2 we have put together differences in the mean positron lifetimes before and after hydrogen ion implantation to dpa and hydrogen concentration profiles calculated by SRIM code.

Results presented in Fig. 2 show a significant shift between the dpa peak and the observed positron lifetime changes. This can be interpreted by some evolution of cavity-type defects in the region of high displacement damage. The increase of positron lifetime along the decrease of intensity of the second component suggests that vacancy-hydrogen agglomerations grow via coalescence, resulting in larger cavities (high $\tau_{2}$ ) with lower number density (low $I_{2}$ ). A similar observation was reported by Dai et al. [17] for 10-20 dpa $\mathrm{Fe} / \mathrm{Cr}$ steels irradiated in spallation neutron target.

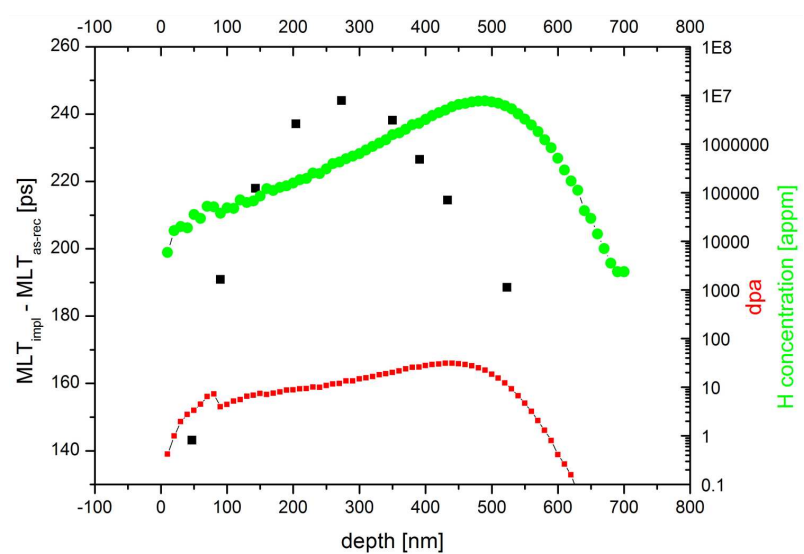

Fig. 2. Comparison difference of positron mean lifetimes values before and after $\mathrm{H}^{++}$implantation of specimen P370 WM to dpa and $\mathrm{H}$ concentration profiles derivedfrom SRIM code.

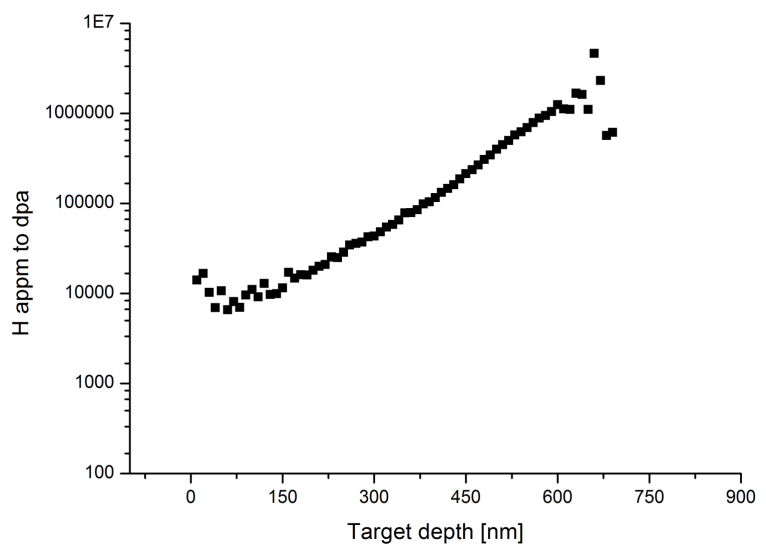

Fig. 3. H/dpa ratio as the function of depth.

Although the dpa and $\mathrm{H}$ ion concentration have peak values between 450 and $500 \mathrm{~nm}$ (Fig. 3), the H-todpa ratio increases exponentially with depth. Similarly, the intensity of the second defect component increases almost monotonically throughout the implanted region. This suggests that hydrogen is required for stabilisation of the radiation-induced defect clusters and with the increased ratio of hydrogen in vacancies, more of the clusters survive recombination processes in the irradiated microstructure.

\section{Conclusion}

We analysed and defined the type of induced damage via hydrogen ion implantation in RPV steel specimens. We focused on the weld material (the specimen P370 WM), which belongs to the first generation of German PWRs, with bigger defects not so homogeneously dispersed, which makes this steel more susceptible to brittle fracture formation than P16 WM steel. 
We tried to simulate neutron irradiation by implantation of hydrogen ions $(100 \mathrm{keV})$ to the P370 WM material. The lifetimes in the defects reached similar values as in neutron-irradiated specimens at a level of $210-230$ ps and the intensity of defects slightly decreased. This trend in behaviour is therefore very similar to neutron-irradiated specimens.

Conventional PALS technique cannot effectively study the near-surface region where hydrogen ions were implanted. Therefore, PLEPS was applied to these specimens as well. After the third level of implantation we achieved approximately the same number of impacted particles like in the neutron-irradiated specimens $\left(\sim 2 \times 10^{19} \mathrm{~cm}^{-2}\right)$, but only in the near surface region up to $600 \mathrm{~nm}$.

Based on our previous PALS results [9], we concluded that no large voids or vacancy clusters were formed due to neutron irradiation in investigated German RPV steels which could cause dangerous embrittlement of RPV and limit the operation of NPPs. Actual hydrogen ion implantation result seems to be similar to the conventional PALS technique point of view, but from the detailed PLEPS analysis (focused only on a thin region destroyed by implantation up to $15 \mathrm{dpa}$ ) formation of huge number of large clusters was observed. The lifetime of defects component $\tau_{2}$ was over 470 ps with intensity $I_{2}$ over $70 \%$ in the maximal implanted region. According to this we can conclude that this type of steel cannot be considered for Gen IV nuclear reactors design materials, where high radiation damage (over $15 \mathrm{dpa}$ ) is expected.

\section{Acknowledgments}

This article was supported by grant VEGA 1/0104/17. This work is based upon experiments performed at the PLEPS instrument operated by FRMII at the Heinz Maier-Leibnitz Zentrum (MLZ), Garching, Germany.

\section{References}

[1] V. Slugen, Safety of VVER-440 Reactors-Barriers Against Fission Products Release, Springer-Verlag, London, 2011.

[2] O. Gokhman, S. Pecko, V. Slugen, Radiation Effects 85 Defects in Solids 170, 130 (2015).
[3] V. Krsjak, J. Degmova, S. Sojak, V. Slugen, J. Nucl. Mater. 499, 38 (2018).

[4] H.P. Zhu, Z.G. Wang, M.H. Cui, B.S. Li, X. Gao, J.R. Sun, C.F. Yao, K.F. Wei, T.F. Shen, L.L. Pang, Y.B.Zhu, Y.F. Li, J. Wang, E.Q. Xie, Appl. Surf. Sci. 326, 1 (2015).

[5] V. Slugen, G. Kögel, P. Sperr, W. Triftshäuser, J. Nucl. Mater 302, 89 (2002).

[6] A. Kryukov, L. Deberberis, A. Ballesteros, V. Krsjak, R. Burcl, S.V. Rogozhkin, A.A. Nikitin, A.A. Aleev, A.G. Zaluzhnyi, V.I. Grafutin, O. Ilyukhina, Y.V. Funtikov, A. Zeman, J. Nucl. Mater. 429, 190 (2012).

[7] V.I. Grafutin, O. Ilyukhina, V. Krsjak, R. Burcl, P. Hähner, D. Erak, A. Zeman, J. Nucl. Mater. 406, (201) 257262.

[8] V. Krsjak, J. Kuriplach, T. Shen, V. Sabelova, K. Sato, Y. Dai, J. Nucl. Mater. 456, 382 (2015).

[9] V. Slugeň, S. Pecko, S. Sojak, J. Nucl. Mater. 468, 285 (2016).

[10] H. Hein, E. Keim, H. Schnabel, T. Seibert, A. Gundermann, J. ASTM Int. 6, 101962 (2009).

[11] R.E. Stoller, M.B. Toloczko, G.S. Was, A.G. Certain, S. Dwaraknath, F.A. Garner, Nucl. Instrum. Methods Phys. Res. Sect. B Beam Interact. Mater. Atoms 310, 75 (2013).

[12] V. Krsjak, J. Degmova, R. Lauko, J. Snopek, M. Saro, K. Sedlackova, S. Sojak, M. Petriska, G. Farkas, Y. Dai, V. Slugen, Nucl. Instrum. Methods Phys. Res. B 434, 73 (2018).

[13] G. Brauer, L. Liszkay, B. Molnar, R. Krause, Nucl. Eng. Design 127, 47 (1991).

[14] J. Cizek, I. Prochazka, J. Kocik, E. Keilova, phys. stat. sol. (a) 178, 651 (2000).

[15] P. Sperr, W. Egger, G. Kögel, G. Dollinger, C. Hugenschmidt, R. Repper, C. Piochacz, Appl. Surf. Sci. 255, 35 (2008).

[16] Ch. Hugenschmidt, Surf. Sci. Rep. 71, 547 (2016).

[17] Y. Dai, V. Krsjak, V. Kuksenko, R. Schaeublin, J. Nucl. Mater. 511, 508 (2018). 